\title{
Chromosome Preparation from Leucocyte Culture A Simplified Method for Collecting Samples by Post
}

\author{
JANET M. ANDERS, ELIZABETH C. MOORES, and RICHARD EMANUEL \\ From the Institute of Cardiology and National Heart Hospital, London W.I
}

A convenient postal method for leucocyte culture was developed during the study of 156 cases of congenital heart disease (Anders, Moores, and Emanuel, 1965). The technique is a simplified version of that reported by Edwards (1963) and is based on his suggestion for the use of dextran to agglutinate the erythrocytes, which makes gravity separation quicker and leaves the majority of the leucocytes suspended in the plasma. Instead of defibrinating by shaking the blood with glass beads for to minutes, as described by Edwards (1963), we used heparin as an anticoagulant. Boots' preparation (Heparin B.P.) proved satisfactory for suppressing clotting throughout incubation. One of the disadvantages of heparin is that fibrin may precipitate during harvesting when hypotonic sodium citrate solution is added. In our experience, however, this does not occur if the original method is used, in which the culture medium containing the cells is diluted with three times its volume of water (Moorhead, Nowell, Mellman, Battips, and Hungerford, 1960). Finally, we found it unnecessary to remove the dextran by centrifuging through sucrose solution after hypotonic treatment (Edwards, 1963), if the cells were washed in several changes of fixative before making the slides.

Dextran was first used in this laboratory when difficulty had been experienced in separating plasma and leucocytes in polycythaemic patients with cyanotic congenital heart disease. Satisfactory separation was achieved in all cases when the whole blood was mixed with dextran, though in patients with a particularly high packed cell volume equal quantities of blood and dextran were necessary. It is now our standard practice for all cultures to add $2 \mathrm{ml}$. dextran to Io $\mathrm{ml}$. whole blood. When

Received May 6, 1965. only small quantities of blood are available the same amount of dextran $(2 \mathrm{ml}$.) can be added to $\overrightarrow{\mathrm{a} s}$ little as I $\mathrm{ml}$. of blood with surprisingly good results.

Phytohaemagglutinin (Burroughs Wellcome) is used only as a mitotic stimulant and not for separ ing the plasma, as described in the standand method (Moorhead et al., 1960). It is therefore added immediately before incubation with tise advantage that cultures may be kept at room temperature until a convenient day for incubation, making week-end harvesting unnecessary.

This technique has been adapted for the coislection of samples by post. The method requires Io $\mathrm{ml}$. blood from venepuncture: this is added $\frac{}{\mathrm{D}} \mathrm{0}$ a bottle containing $0.1 \mathrm{ml}$. Heparin (Boots', 5,000 units per $\mathrm{ml}$. in normal saline) in $2 \mathrm{ml}$. dextra (Benger's Dextraven : 6\% dextran in saline average

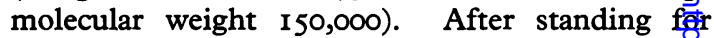
15-30 minutes the erythrocytes sediment and thie supernatant plasma with leucocytes is then transferred with a fresh syringe and needle to a secongd bottle containing $5 \mathrm{ml}$. tissue culture medium ' $199 \mathrm{~g}$.' (Glaxo). If the blood is left to stand for as loing as one hour the leucocytes may also sediment forming a buffy coat, which makes separation difficult. It is possible to remedy this by shaking the blood and leaving it to settle again, though sole of the leucocytes will be lost by this treatme Both bottles are then posted to the laboratosy where the culture is set up and incubated in the usual way.

A total of 26 samples has been obtained by post and 23 were cultured successfully. The average time between taking the blood and incubation we 3 days. The maximum delay was 5 days, whe्gh two cultures were mislaid on arrival at the hospital. One of these grew satisfactorily, the other failed. There was no apparent technical reason for the failure of the other two unsuccessful cultures. 
A postal pack for a single culture contains:

Bottle A: $0.1 \mathrm{ml}$. Heparin in $2 \mathrm{ml}$. dextran

Bottle B: 5 ml. T.C. medium ' 199 '

2 disposable syringes ( $10 \mathrm{ml}$.)

I disposable needle for taking blood

$\left.\begin{array}{l}2 \text { long needles } \\ 2 \text { air vents }\end{array}\right\}$ for addition of blood to bottles

Alcohol and cotton wool for cleaning skin and bottles

Instruction sheet.

Bottles $\mathrm{A}$ and $\mathrm{B}$ can be kept in a refrigerator at $4^{\circ} \mathrm{C}$. for two weeks. Storage for longer periods has not been investigated.
We should like to express our gratitude to the Nuffield Foundation for supporting the Cytogenetics Laboratory at the Institute of Cardiology.

\section{REFERENCES}

Anders, J. M., Moores, E. C., and Emanuel, R. (1965). Chromosome studies in 156 patients with congenital heart disease. Brit. Heart f., 27, 756.

Edwards, J. H. (1963). Chromosomal investigation by post. Lancet, I, 725 .

Moorhead, P. S., Nowell, P. C., Mellman, W. J., Battips, D. M., and Hungerford, D. A. (1960). Chromosome preparations of leukocytes cultured from human peripheral blood. Exp. Cell Res.,
20, 613 . 